\title{
PENERAPAN KEPEMIMPINAN MELAYANI (SERVANT LEADERSHIP) BIDANG PENGUATAN KARAKTER GURU DAN SISWA
}

\author{
Sri Wening Rahayu, \\ Conny Benyamin \\ Universitas Kanjuruhan Malang \\ Email:weningmukiyo@gmail.com
}

\begin{abstract}
This study focused on issues including: (1) the values that underlie service leadership or servant leadership (2) the application of service leadership or servant leadership and (3) the impact of implementing service leadership or servant leadership on the character of teachers and students at SD Shinning Star Malang and Malang Aletheia Elementary School. This research uses a qualitative research approach, descriptive type, with a multi-site study research type. Data collection techniques used were in-depth interviews, participant observation and documentation. The research subjects are the principal, teachers, parents and administrators of the foundation. The data validity technique used is credibility, discussion with peers, member checks, dependability and confirmability. Data analysis techniques include reduction, data display, and verification. The results showed serving leadership implemented by schools based on value people, develop people, build community, display authenticity, provide leadership, and share leadership.
\end{abstract}

Keywords: servant leadership, character, christian elementary school

\begin{abstract}
Abstrak: Penelitian ini difokuskan pada permasalahan antara lain: (1) nilai-nilai yang mendasari kepemimpinan pelayanan atau servant leadership (2) penerapan kepemimpinan pelayanan atau servant leadership dan (3) dampak penerapan kepemimpinan pelayanan atau servant leadership terhadap karakter guru dan siswa di SD Shinning Star Malang dan SD Aletheia Malang. Penelitian ini menggunakan pendekatan Penelitian kualitatif, tipe deskriptif, dengan jenis penelitian studi multi situs. Teknik pengumpulan data yang digunakan adalah wawancara mendalam, observasi partisipan dan dokumentasi. Subyek penelitiannya adalah kepala sekolah, guru, orang tua dan pengurus yayasan. Teknik keabsahan data yang digunakan adalah kredibilitas, diskusi dengan teman sejawat, member chek, dependabilitas dan konfirmabilitas. Teknik analisis data mencakup reduksi, penyajian data, dan verifikasi. Hasil penelitian menunjukkan kepemimpinan melayani yang diterapkan oleh sekolah yaitu berdasarkan value people, develop people, build community, display authenticity, provide leadership, dan share leadership.
\end{abstract}

Kata kunci: Kepemimpinan melayani (servant leadership), karakter siswa, SD Kristen

Sekolah sebagai suatu institusi pendidikan sangat sarat dengan sistem organisasi yang sifatnya hierarki atau "top down". Dimana struktur organisasinya bertingkat sifatnya, yaitu segala peraturan dan kebijakan diberikan dari atasan kepada bawahan. Kepala sekolah pada umumnya dibanyak sekolah sebagai pimpinan tertinggi. Dengan sistem organisasi demikian guru perannya adalah sebagai pelaksana tugas yang hanya melaksanakan instruksi dari kepala sekolah. Ada banyak kasus di sekolah, guru-guru menjadi pasif dan cenderung menurut saja apa kata kepala sekolah. Kondisi seperti ini lambat laun akan menghambat perkembangan dan kemajuan guru sebagai pendidik. Padahal sebagai pelaksana guru-guru berhadapan langsung 
dengan siswa-siswa yang menjadi tanggung jawabnya untuk dididik dan dibimbing. Jika guru tidak dipimpin dan didampingi dengan baik dan proposional maka hal itu juga akan berimbas kepada mutu pendidikan siswa. Sehingga hal ini terkait dengan keberadaan seorang kepala sekolah sebagai pemimpin yang menentukan pola kepemimpinannya, dan mempengaruhi gerak kebijakannya.

$$
\text { Kepemimpinan adalah proses }
$$

mempengaruhi kegiatan-kegiatan kelompok yang diorganisir menuju pada penentuan dan pencapaian tujuan (Rosmiati, dkk, 2012). Menurut Sandjaya dan Sarros (2002) bahwa seorang yang menduduki kepemimpinan formal belumlah tepat di sebut 'pemimpin' jika mereka tidak menjalankan fungsinya sebagai pemimpin. Karena kepemimpinan tidak sama dengan posisi. Yang disebut kepemimpinan adalah fungsi. Seperti yang Kofi Annan (sekretaris PBB) kemukakan di Human Development Report yang di rilis UNDP (United Nations Development Programm bahwa hambatan terhadap sebuah kepemimpinan tidak ada hubungannya dengan budaya atau agama, dan lebih banyak lagi yang berkaitan dengan keinginan sang pemimpin untuk mempertahankan posisi mereka dengan cara apapun., sehingga pernyataan ini membuka kenyataan kegagalan pemimpin formal. Untuk membuktikan apakah seorang pemimpin itu berhasil harus dilihat dari orang-orang yang dilayani apakah semakin bertumbuh sebagai suatu pribadi yang makin sehat, bijaksana, merdeka, lebih mandiri dan mereka juga menjadi pelayan bagi orang lain. (R. Greenleaf 1970)

Spears (1995) yang berpendapat bahwa Servant Leadership adalah pendekatan dari seorang pemimpin yang berdampak secara langsung dimana terjadi transformasi kehidupan yang terpancar dalam kehidupan mereka, Spears menyaring ide SL dari R.Greenleaf menjadi 10 karakter SL, yaitu Listening (mendengarkan, empathy (empati), healing (menyembuhkan), awareness (kesadaran), persuasion (persuasif), conceptualization (konseptualisasi), foresight (melihat ke masa depan), stewardship (penatalayanan), commitment to growth (komitmen untuk pertumbuhan) dan community building (pembangunan komunitas).

Pada penelitian yang dilakukan di Pakistan tentang dampak komitmen organisasi terhadap loyalitas karyawan yang dilakukan oleh lqbal dkk (2015) didapatkan hasil bahwa terdapat pengaruh positif dan signifikan dari komitmen organisasi terhadap loyalitas karyawan. Dimana menurut peneliti komitmen organisasi memiliki peranan penting dalam loyalitas yang dimiliki oleh karyawan, selain itu organisasi wajib memberikan manfaat dan insentif terhadap para karyawan agar karyawan yang memiliki perilaku yang kurang baik mampu memperbaiki perilakunya serta memiliki komitmen terhadap organisasi atau perusahaan dimana ia bekerja. Komitmen karyawan terhadap organisasi atau tempat ia bekerja dapat dipengaruhi oleh berbagai macam faktor salah satunya adalah gaya seorang pemimpin dalam mengendalikan atau memimpin perusahaannya. Pemimpin memiliki peran yang tak kalah penting sebagaimana peran yang diberikan oleh karyawan atau pegawai, dimana pemimpin sangat menentukan bagi perkembangan dan kelangsungan hidup dari suatu perusahaan (Ancok, 2012).

Menjadi kepala sekolah seharusnya mampu meninggalkan kehidupan duniawi untuk mengabdikan diri seutuhnya demi layanan yang berkualitas (Trompenaars \& Voerman, 2009). Ketika menjadi kepala sekolah benar-benar memiliki komitmen untuk tidak menikah seumur hidup. Menjadi kepala sekolah mempunyai pemikiran yang dewasa, bertanggungjawab dan memberikan dampak yang positif kepada rekan kerjanya. Perilaku kepemimpinan mampu memberikan pelayanan yang berkualitas terhadap rekan kerja, staf maupun peserta didik (Crippen \& Jessica, 2019). Sebagai pemimpin mampu menciptakan komunikasi yang baik dan dapat memberikan solusi terhadap 
permasalahan yang dihadapi rekan kerja maupun staf di sekolah (Kolb, 2018).

Dalam sejarah pendirian sekolahsekolah Kristen rata-rata sekolah yang didirikan oleh gereja bertujuan untuk mewujudkan misi pendidikan yang melayani masyarakat, termasuk SD Kristen Shinning STAR Malang dan SD Kristen Aletheia Malang. Sebagai sekolah yang didirikan oleh gereja dengan berbasis pelayanan, sejauh mana sekolah tersebut telah memiliki seorang kepala sekolah yang sudah menerapkan prinsip-prinsip/nilai-nilai servant leadership dalam melaksanakan tugasnya adalah hal yang patut diteliti, karena dapat berdampak pada pembentukan karakter guru dan siswanya. Adapun yang menjadi tujuan penelitian ini ada 3 fokus yaitu mendeskripsikan (1) nilainilai yang mendasari kepemimpinan pelayanan atau servant leadership, (2) penerapan kepemimpinan pelayanan atau servant leadership, dan (3) dampak penerapan kepemimpinan pelayanan atau servant leadership terhadap karakter guru dan siswa di SD Shinning Star Malang dan SD Aletheia Malang.

\section{METODE}

Penelitian ini menggunakan pendekatan kualitatif tipe deskriptif, dengan jenis penelitiannya adalah studi multi situs. Moleong (2007: 248), Rancangan studi multi situs merupakan salah satu bentuk rancangan yang digunakan untuk mengembangkan teori yang diangkat dari beberapa latar penelitian yang serupa, sehingga dapat dihasilkan teori yang dapat ditransfer ke situasi yang lebih luas dan lebih umum cakupannya (Ulfatin, 2015). Subjek penelitian dalam penelitian kali ini adalah kepala sekolah, guru, dan orang tua siswa. Data dikumpulkan melalui wawancara, observasi, dan studi dokumentasi.

Analisis data kualitatif adalah upaya yang dilakukan dengan jalan bekerja dengan data, mengorganisasikan data, memilah-milahnya menjadi satuan yang dapat dikelola, mensintesiskannya, mencari dan menemukan pola, menemukan apa yang penting dan apa yang dipelajari dan memutuskan apa yang dapat diceritakan kepada orang lain. Miles, dkk (2014) mengemukakan bahwa analisis terdiri dari tiga alur kegiatan yang terjadi secara bersamaan, yaitu: kondensasi data, penyajian data dan penarikan kesimpulan atau verifikasi. Kegiatan reduksi data, penyajian data dapenarikan kesimpulan atau verifikasi dilakukan sebelum, selama dan sesudah pengumpulan data dalam bentuk sejajar untuk membangun suatu analisis yang tangguh.

\section{HASIL DAN PEMBAHASAN}

Nilai-Nilai yang Mendasari
Kepemimpinan Pelayanan Atau Servant
Leadership

Berdasarkan hasil temuan Penelitian tahun 2019, nilai-nilai yang mendasari kepemimpinan pelayanan atau servant leadership di SD Kristen Aletheia Malang dan SD Kristen Shinning Star Malang adalah nilai-nilai yang diajarkan oleh Tuhan Yesus Kristus yang diyakini sebagai pemimpin agung, The Master Teacher yang menghimbau yaitu seorang pemimpin itu hendaknya punya prinsip 'melayani bukan dilayani'”, yang pada hakekatnya menghasilkan nilai-nilai mengasihi sesama, termasuk dalam hal ini pendidik, peserta didik dan tenaga kependidikan di sekolah, keiklhasan dalam bekerja, kedisiplinan dalam melaksanakan tugas, kesungguhan hati dalam berkomitmen dan bekerja keras sebagai gaya hidup, mengutamakan kebutuhan dan kepentingan komunitas sekolah lebih dari sekedar target kerja yang diinginkan, bahkan seorang pemimpin yang diharapkan memiliki sikap yang rela mendengar, memahami, menganalisis dan memecahkan masalah secara bersamasama, saling mendukung dan menguatkan, bukan memaksa namun bisa mempengaruhi serta memberi teladan terlebih dahulu bagi komunitas sekolah. Temuan tersebut sesuai dengan yang 
dikemukakan oleh Spears (1998) dan Greenleaf dan Contee-Boders (2003) bahwa nilai-nilai kepemimpinan yang melayani antara lain: (1) pemimpin yang mendengar - pelayan mengklarifikasi kehendak suatu kelompok dengan mendengarkan secara reseptif apa yang dikatakan; (2) pemimpin empati - pelayan berusaha untuk memahami dan berempati dengan orang lain; (3). penyembuhan pemimpin pelayan memiliki potensi untuk menyembuhkan diri sendiri dan orang lain; (4) kesadaran - kepemimpinan pelayan diperkuat oleh kesadaran umum, dan terutama kesadaran diri; (5). persuasi pemimpin pelayan mengandalkan pada persuasi, bukan otoritas posisi, dalam membuat keputusan dalam suatu organisasi; (6) konseptualisasi - pemimpin pelayan berusaha untuk memelihara kemampuan mereka untuk memimpikan mimpi-mimpi besar; (7). pandangan ke depan - pemimpin pelayan memiliki kemampuan untuk melihat kemungkinan hasil dari suatu situasi di masa depan; (8) penatalayanan - komitmen pemimpin yang pertama dan terpenting adalah melayani kebutuhan orang lain; (9) komitmen terhadap pertumbuhan orang - pemimpin yang melayani sangat berkomitmen pada pertumbuhan pribadi, profesional, dan spiritual dari setiap individu di dalam institusi; dan (10) membangun pemimpin masyarakat - pelayan berusaha mengidentifikasi cara membangun. komunitas di antara mereka yang bekerja dalam lembaga tertentu. Pernyataan tersebut juga didukung oleh hasil penelitian bahwa servant leadersip merupakan bentuk kepemimpinan yang dapat menghidupkan organisasi, sebagaimana yang disebutkan dalam penelitian yang dilakukan oleh Parolini, dkk (2009).

Menurut Greenleaf (2003) seorang pemimpin dalam membangun komunitas mampu bekerja secara kolaboratif. Pemimpin mampu mengarahkan kelompok untuk bekerja secara professional. Selain itu mereka juga trampil dalam menjalin dan membangun hubungan sosial yang harmonis dalam komunitas. Sehingga komunitas yang dibangun memiliki kesatuan hati, keterikatan dan menyatukan visi dalam mencapai tujuan bersama.

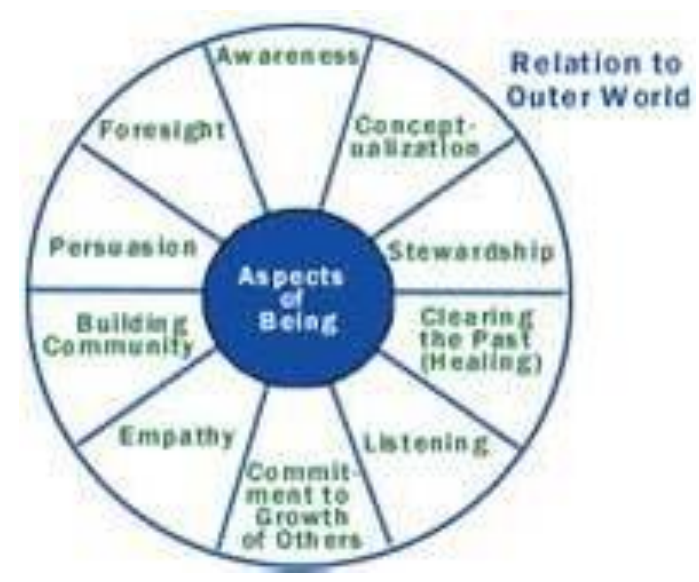

Gambar 1. Nilai-nilai Servant Leadership

Berdasarkan hasil Penelitian ditemukan bahwa nilai-nilai yang mendasari pelaksanaan kepemimpinan melayani atau servant leadership, memang belum semua diterapkan secara lengkap, namun sebagian besar sudah mencakup, dan yang lain terus diupayakan realisasinya. Dan terus disosialisasi dan diberi teladan aoleh kepala sekolah.

\section{Penerapan Kepemimpinan Pelayanan atau Servant Leadership di Sekolah Penerapan kepemimpinan} Pelayanan atau Servant Leadership di SD Kristen Aletheia Malang dan SD Kristen Shinning Star Malang, sudah cukup memadai hak ini terlihat pada bagaimana kepala sekolah selalu memahami kondisi personal orang yang dipimpinnya, melalui pemahaman latar belakang para siswa dan situasi orang tua, melalui beberapa pendekatan yang dilakukan oleh kepala sekolah sebagai berikut: pendekatan psikologis, pendekatan keteladanan, keterlibatan, pendampingan, tindakan real dan penciptaann iklim yang kondusif baik di sekolah, kelas, kantor dan aksi sosial pada masyarakat sekitar sekolah. Hal ini sesuai dengan Gambar 2. 
Karakteristik model Servant Leadership yang dikembangkan adalah: (1) Value People (Nilai orang). Perhatian kepada orang adalah hal yang utama. Nilai kemanusiaan dalam kepemimpinan yang melayani merupakan prioritas tertinggi. Pada saat membuat keputusan dan menerapkan aturan nilai kemanusiaan menjadi pertimbangan yang penting. (2) Develop People (mengembangkan orang). Dalam kepemimpinan yang melayani perhatian kepada tumbuh kembang tiap individu menjadi agenda yang utama. Pemimpin memperhatikan, merencanakan, mendorong dan memfasilitasi tiap anggotanya untuk bertumbuh dan berkembang. (3) Build Community (membangun komunitas). Dalam kepemimpinan yang melayani, pemimpin sadar bahwa dia tidak dapat bekerja sendiri. Untuk mencapai tujuan yang maksimal diperlukan teamwork. Pemimpin harus membangun komunitas yang dapat saling bekerjasama, memiliki visi yang sama dan mau diajak untuk bertumbuh dan berkembang secara dinamis. (4) Display Authenticity (tampilan yang asli/apa adanya). Tampilan seorang pemimpin yang melayani haruslah otentik. Baik dari segi karakter maupun integritas hidupnya, apa yang dikatakannya harus sesuai dengan apa yang diperbuatnya. Karena yang dibutuhkan dari kepemimpinan yang melayani adalah contoh dan teladan yang ditampilkannya. Kejujuran dan keterbukaan dari pemimpin sangat dituntut dalam hal ini. Sehingga anggota dapat melihat secara nyata ketulusan hati dari pemimpin yang sungguh-sungguh ingin memberikan yang terbaik. (5) Provide Leadership (memimpin). Kepemimpinan yang melayani haruslah memiliki kemampuan memimpin. Dibalik sikap hati yang tulus melayani, pemimpin harus dapat memberikan visi, merencanakan, mengorganisir, mengarahkan, mengatur dan mengkoodinasi. Dan (6) Share Leadership (berbagi kepemimpinan). Dalam kepemimpinan yang melayani tanggung jawab pemimpin tidak diletakkan hanya kepada satu personil, tetapi dibagikan kepada yang lain. Pemimpin dapat membagikan beban dan tanggungjawab kepada anggotanya, khususnya anggota yang sudah terseleksi dan memiliki kemampuan dalam memimpin. Dari hasil temuan Penelitian dapat diuraikan bahwa penerapan kepemimpnan melayani di dua sekolah tersebut sudah sebagian besar diterapkan, walau belum maksimal, tapi terus akan diupayakan peningkatannya menjadi lebih baik lagi.

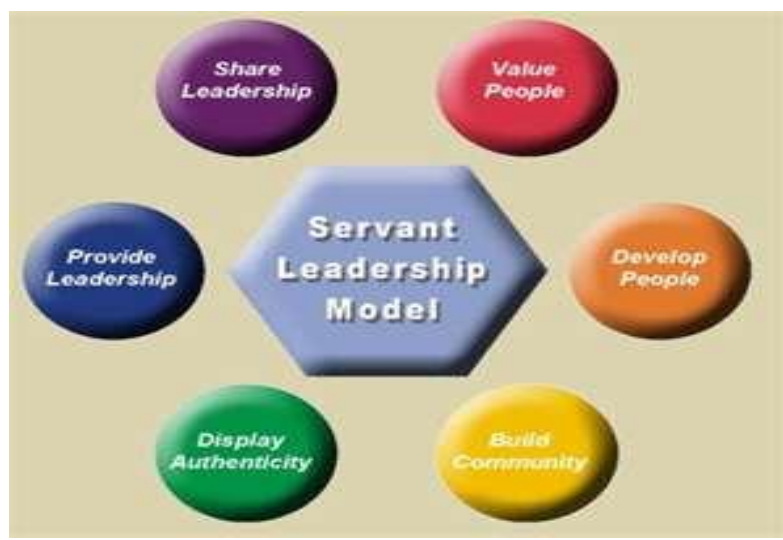

Gambar 2. Bagan model Servant Leadship for clarity (Malaysia today.net)

Dampak Kepemimpinan Melayani atau Servant Leadership bagi Karakter Guru dan Siswa di Sekolah.

Berdasarkan temuan Penelitian dapat disimpulkan bahwa penerapan kepemimpinan melayani atau servant leadership di SD Kristen Aletheia Malang dan S D Kristen Shinning Star Malang berdampak pada karakter dan kinerja guru serta karakter siswanya. Dampaknya berupa guru memiliki etos kerja yang positif yaitu melayani bukan dilayani, guru lebih bekerja keras untuk memenuhi tugas dan kewajiban pembelajaran maupun kedinasan, guru lebih terfokus pada panggilan seorang guru dan bersedia dengan ikhlas meningkatkan mutu mengajarnya demi layanan terbaik bagi oeserta didiknya, bahkan dengan tindakan real juga guru tergerak membantu kebutuhan ekonomi sesuai dengan kemampuannya apabila siswa dalam 
DOI : 10.26740/jdmp.v5n1.p29-35

kesulitan (Astuty, 2015). Sedangkan dampak penerapan kepemimpinan melayani atau servant leadership bagi siswa di kedua sekolah dasar tersebut, mereka menunjukkan karakter sebagai berikut: cepat tanggap jika dimintai tolong, suka berbagi, tidak membeda-bedakan teman saat bergaul, semangat beribadah, dan terlibat dalam acara ibadah, jujur jika meminjam sesuatu atau saat menemukan barang hilang, suka menyapa bila bertemu orang, berempati, suka menyemangati guru dan teman.

Dari hasil Penelitian tersebut memang merujuk pada pembentukan karakter yang dikemukakan oleh Lickona (2013) menekankan pentingnya tiga kompunen karakter yang baik, yaitu moral knowing atau pengetahuan tentang moral, moral feeling (perasaan tentang mental, dan moral action atau perbiatan moral. Hal ini diperlukan agar seseorang mampu memahami, merasakan, dan mengerjakan sekaligus nilai-nilai kebajikan. Moral knowing yaitu: kesadaran moral, pengetahuan nilai-nilai moral, penentuan persepsi, pemikiran moral, pengambilan keputusan dan pengetahuan sendiri tentang moral. Moral feeling yaitu: nurani, harga diri, empati, mencintai kebenaran, mampu mengontrol diri dan kerendahan hati. Sedangkan yang dimaksud dengan moral action atau tindakan nyata yang terdiri dari tiga aspek karakter, yaitu: kompetensi, keinginan dan kebiasaan. Walaupun dampaknya masih sederhana, namun sangat mempengaruhi penguatan karakter bagi guru dan siswa di SD Kristen tersebut, sehingga diharapkan sudah menjadi ciri khas dari kepemimpinan melayani dan visi misi sekolah bisa tercapai.

\section{KESIMPULAN}

Berdasarkan hasil penelitian, dapat disimpulkan bahwa: (1) nilai-nilai yang mendasari dilaksanakannya kepemimpinan melayani atau servant leadership di SD Kristen Alethia Malang dan SD Kristen Shinning Star Malang antara lain: mengikuti nilai-nilai yang diajarkan oleh Tuhan Yesus
Kristus yang diyakini sebagai pemimpin agung, The Master Teacher yang menghimbau yaitu seorang pemimpin itu hendaknya punya prinsip 'melayani bukan dilayan", mewujudkan visi misi sekolah, dan menempatkan keteladalan dari pemimpin serta mengikuti ciri-ciri kepemimpinan sevant leadership sebagaimana seharusnya; (2) penerapan kepemimpinan melayani atau servant leadership, di SD Kristen Alethia Malang dan SD Shinning Star Malang cukup memadai dengan bukti tindakan real yang dilakukan mulai dari kepala sekolah dan komunitas sekolah serta unguk masyarakat sekitarnya; dan (3) dampak kepemimpinan melayani atau servant leadership bagi guru dan siswa nyata dalam karakter dan dinyatakan dalam tindakan sehari-hari khususnya saat beradadi lingkungan sekolah.

\section{SARAN}

Berdasarkan uraian dari pada bab-bab sebelumnya dan simpulan di atas, maka dikemukakan saran yang menjadi bahan masukan baik bagi SD Kristen Aletheia Malang maupun bagi SD Kristen Shinning Star Malang yaitu: (1) bagi kepala sekolah dan pihak yayasan turus mempertahankan nilai-nilai keteladanan yang menggambarkan nilai-nilai kepemimpinan melayani atau servant leadership, karena melaluinya dapat berdampak bagi pembentukan karakter komunitas sekolah. Hal ini bisa diwujudkan pula dengan adanya program dan kegiatan penguatan karakter yang real; (2) guru-guru Di SD Kristen Aletheia Malang dan SD Kristen Shinning Star Malang, terus memiliki semangat melakukan gaya melayani dan memberi yang terbaik dalam melayani peserta didiknya, karena sangat mempenaruhi pembentukan karakternya. Sehingga selalu semangat dalam melaksanakan kinerjanya; dan (3) para siswa SD Kristen Aletheia Malang dan SD Kristen Shinning Star lebih bersemangat belajar dan melakukan nilainilai servant leadership dimanapun mereka berada. 


\section{DAFTAR RUJUKAN}

Ancok, D. 2012. Psikologi Kepemimpinan dan Inovasi. Jakarta: Penerbit Erlangga Astoha

Astuty E. 2015. Implementation Analysis of Lecturer's Pedagogical Competence on Student's Academic Achievement. Journal of Management Research 7.

Crippen, C., \& Jessica, W. 2019. Connecting Teacher Leadership and Servant Leadership A Synergetic Partnership. Journal of Leadership Education: University of Victoria.

Greenleaf, R \& Boders, C. 2003. The Servant Leader Within: A Transformative Path. Mahwah, NJ: Paulist Press

Iqbal, N., Anwar, S., \& Haider, N. 2015. Effect of Leadership Style on Employee Performance. Arabian Journal Business Management Review. ISSN: 2223-5833.

Kolb, J. C. 2018. A Qualitative Descriptive Study of a Servant Leadership Training Program for College Students. A Dissertation Presented in Partial Fulfullment of the Requiremenst or the degree Doctorate of Education. Phoenix, Arizona: Grand Canyon University

Lickona, T. 2013. Pendidikan Karakter: Panduan Lengkap Mendidik Siswa. Menjadi Pintar dan Baik. Bandung: Penerbit Nusa Media.
Miles, M. B., Huberman, A. M., \& Saldana, J. 2014. Qualitative Data Analysis: A Methods Sourcebook. London: Sage.

Moleong, L. J. 2007. Metodologi Penelitian Kualitatif. Bandung: PT Remaja Rosdakarya.

Parolini, J., Patterson, K., \& Winston, B. 2009. Distingushing Between Transformational and Servant Leadership. Leadership \& Organization Development Journal, 30(3), 274-291.

Rosmiati, T. \& Kurniadi, D. A. 2012. Kepemimpinan Pendidikan. Dalam Tim Dosen Administrasi Pendidikan UPI. Manajemen Pendidikan. Bandung: Alfabeta.

Sandjaya, S. \& Sarros, J. C. 2002. Servant leadership: Its Origin, Development and Application in Organizations. Journal of Leadership and Organization Studies.

Spears, L. 2002. Character and Servant Leadership: Ten Characteristics of Effective, Caring Leaders. The Journal of Virtues \& Leadership.

Trompenaars, F., \& Voerman. Servant Leadership Across Cultures: Harnessing The Strength of The World's Most Powerful Leadership Philosophy, Ed 2009. New York: Infinite Ideas Limited.

Ulfatin, N. 2015. Metode Penelitian Kualitatif di Bidang Pendidikan: Teori dan Aplikasinya. Malang: Media Nusa Kreatif. 